\title{
The effect of a furnished individual hutch pre-weaning on calf behavior, response to novelty, and growth
}

\author{
J. A. Pempek, ${ }^{*}$ M. L. Eastridge, $†$ and K. L. Proudfoot*1 \\ *Department of Veterinary Preventive Medicine, and \\ †Department of Animal Sciences, The Ohio State University, Columbus 43210
}

\begin{abstract}
Housing preweaned dairy calves in individual outdoor hutches is common in North America. However, this type of housing lacks stimulation and minimizes calves' ability to express natural behavior. Providing a social companion has been shown to stimulate natural behavior and promote growth, but no research has assessed the effect of providing physical enrichment items to calves pre-weaning. The objective of this study was to determine calf use of physical items added to an individual hutch, and if providing these items affected growth, behavior (e.g., locomotor play and sucking on pen fixtures), and response to novelty after weaning. At birth, Jersey heifer calves were allocated to 1 of 2 types of hutches: furnished ( $\mathrm{n}=9$ calves) or standard ( $\mathrm{n}=$ 10 calves). Calves were housed in individual hutches on loose gravel and bedded with straw. The outdoor enclosure of furnished hutches contained 2 artificial teats, a stationary brush, a calf "lollie," and a rubber chain link for calves to manipulate. Calves were videorecorded continuously between 0800 and $2000 \mathrm{~h}$ twice weekly at $1,3,5$, and 7 wk of age; behavioral data were collected using the Noldus Observer software program (Noldus Inc., Wageningen, the Netherlands). At 63 d of age (after weaning), calf response to social and environmental novelty was tested. Starter consumption was measured daily, and calves were weighed at birth and weekly thereafter. Pre-weaning behavioral data were not normally distributed, so raw data were square-root-transformed before analysis. Calves used all of the items depending on the time of day, but they spent the most time using the brush. Calves housed in furnished hutches spent almost $50 \%$ more time engaged in locomotor play, but they spent the same amount of time sucking pen fixtures as calves housed in standard hutches. We observed no effect of treatment on growth, starter intake, or behavioral response to social and
\end{abstract}

Received October 19, 2016.

Accepted February 26, 2017.

${ }^{1}$ Corresponding author: proudfoot.18@osu.edu environmental novelty after weaning. Results suggest that providing some physical complexity to a standard hutch has some benefits for young calves, but further research is encouraged to determine the long-term effects of physical and social complexity for young dairy heifer calves.

Key words: calf, behavior, enrichment

\section{INTRODUCTION}

Most dairy calves in the United States are housed in individual pens or hutches before weaning (USDA, 2016). However, individual housing lacks physical and social stimulation, limiting calves' ability to perform natural behaviors (Stull and Reynolds, 2008). Interest has increased in improving barren conditions for dairy calves and other farm animals by enriching the animals' environment using social, physical, sensory, and nutritional methods (see Mandel et al., 2016, for a review). Effective enrichment should include modifications that improve health, promote natural behavior, reduce abnormal behavior, or provide other benefits compared with minimum housing standards (Newberry, 1995; Mandel et al., 2016). Recent research has shown benefits from the social housing of calves (De Paula Vieira et al., 2012; Galliard et al., 2014), but less research has focused on other forms of enrichment, such as adding complexity to their physical environment.

Standard hutches are usually barren, which likely limits natural calf behaviors such as play and grooming. Play behavior is normal in calves and is considered an indicator of positive welfare (Jensen et al., 1998; Boissy et al., 2007; Mintline et al., 2013). Play can be stimulated by external factors (such as the addition of fresh bedding to a pen) and by space allowance (Jensen et al., 1998), but less is known about the effect of additional objects on calf play. Grooming behavior has been under-researched in dairy calves, but there is growing evidence that adult cows are motivated to access a brush and use it to groom places on their body that are difficult to reach (DeVries et al., 2007; ValLaillet et al., 2008). 
In addition to individual housing, a second standard practice for young dairy calves in the United States is the provision of milk or milk replacer in open buckets (USDA, 2016). Young calves have a strong, innate motivation to suckle, and without an appropriate outlet for sucking (e.g., because of feeding in open buckets), they redirect their sucking behavior to fixtures in the pen or their peers (Jensen and Budde, 2006; Pempek et al., 2016). Feeding calves from buckets with teat attachments or providing an artificial teat after a meal reduces non-nutritive sucking (Rushen and de Passillé, 1995; Veissier et al., 2002).

Another potential benefit to increasing the complexity of the physical environment of a hutch is improved response to novelty Evidence from calves and laboratory animals suggests that increasing the complexity of the environment can affect the animal's response to novelty (e.g., De Paula Vieira et al., 2012; Zimmermann et al., 2001). For example, calves housed with a partner pre-weaning were less reactive to environmental and social novelty (De Paula Vieira et al., 2012). Although social and physical enrichments are very different, an investigation of the effect of physical enrichment on response to novelty is warranted in calves.

More physical complexity in a farm animal's environment may also improve feed intake and growth. Although little research has been done with calves, research using pigs has determined that the addition of extra space and an area with peat and straw improved feed intake and food conversion ratios compared with pigs housed in standard pens (Beattie et al., 2000). Research is needed to determine whether physical enrichments added to a standard hutch can also affect calf growth early in life.

The overall goal of this study was to assess the use and effect of physical enrichment items (chosen to stimulate grooming, play, and oral behaviors) in a furnished hutch compared with a standard hutch. Our specific objectives were to (1) determine the duration and frequency of item use by calves; (2) determine the effect of the furnished hutch on calf behavior; (3) determine the effect of the furnished hutch on calves' response to environmental and social novelty post-weaning; and (4) determine the effect of the furnished hutch on starter intake and growth.

\section{MATERIALS AND METHODS}

This study was conducted at the Ohio State University's Waterman Dairy Center, located in Columbus, Ohio, in accordance with the guidelines set by the Institutional Animal Care and Use Committee (Animal Use Protocol: 2015A00000050).

\section{Animals, Housing, and Feeding}

Nineteen female Jersey calves were used in this study from birth to 9 wk of age $(63 \mathrm{~d})$. The study began in June 2015 and ended in September 2015. Calves were housed in individual hutches (Calf-Tel Deluxe, Hampel Corp., Germantown, WI) with a wire panel pen enclosure $(1.22 \times 2.72 \mathrm{~m})$. Hutches were placed on loose gravel and bedded with straw; straw was added weekly to each hutch and was completely cleaned and changed between calves. Hutches were placed approximately 0.6 $\mathrm{m}$ from each other in 2 rows; calves had visual contact with at least one other calf at all times, but they had no physical contact with each other during the preweaning period.

All calves received $1.9 \mathrm{~L}$ of colostrum through a bottle as soon as possible after birth and again within $6 \mathrm{~h}$ of the first colostrum feeding, per regular farm standard operating procedures. If colostrum of acceptable quality $(>50 \mathrm{mg} / \mathrm{mL} \mathrm{IgG}$, measured using a colostrometer) was not available, a colostrum replacement (bovine IgG, colostrum replacement; Land O'Lakes Animal Milk Products, Shoreview, MN) was fed to the calf. As part of the farm's normal practice, total proteins in plasma were measured from each calf to determine passive transfer (see Pempek et al., 2016, for a description of this process). All calves enrolled in the experiment had adequate passive transfer (total proteins $\geq 5.2 \mathrm{~g} /$ dL; Dawes et al., 2002).

Calves were fed milk replacer (Cow's Match Jersey Blend; $28 \% \mathrm{CP}$ and $25 \%$ fat, as-fed basis; Land O' Lakes Animal Milk Products) twice daily at approximately 0500 and $1700 \mathrm{~h}$ using an open bucket; buckets were removed and cleaned after the calves completed their milk meal. During the first $7 \mathrm{~d}$ of life, calves were fed $1.89 \mathrm{~L}$ of milk replacer per feeding $(3.78 \mathrm{~L} / \mathrm{d})$, and then $2.27 \mathrm{~L}$ per feeding thereafter $(4.5 \mathrm{~L} / \mathrm{d})$. Gradual weaning from milk replacer began on d 49 of age; calves were decreased to 1 milk feeding (morning feeding only) per day for $7 \mathrm{~d}$. All calves were weaned on $\mathrm{d} 56$, and remained in hutches until d 63 of age.

Throughout the experiment, calves had ad libitum access to texturized starter (22\% CP; AMPLI-Calf Jersey Blend, Land O'Lakes Purina Feed LLC, Shoreview, MN) medicated with $44 \mathrm{~g} / \mathrm{t}$ of monensin (Rumensin; Elanco Animal Health, Greenfield, IN) and ad libitum access to water. The daily ambient temperature $\left({ }^{\circ} \mathrm{F}\right)$ and relative humidity were recorded from 0800 to $2000 \mathrm{~h}$ at the Columbus station of the Ohio Agricultural Research and Development Center from June to September 2015; these records were used to calculate temperature-humidity index (THI; mean \pm SD $=$ $81.3 \pm 7.13$ THI; minimum $=67.0 ;$ maximum $=92.9$; Zimbelman and Collier, 2011). The THI was recorded 
and included in the analysis of behavior, because we anticipated that calves would be generally less active when THI was high.

\section{Experimental Design and Treatments}

Calves were matched with a partner by day of birth, and 1 of each pair was randomly allocated to 1 of 2 types of hutches: furnished ( $\mathrm{n}=9$ calves) or standard $(\mathrm{n}=10$ calves $)$. One calf initially enrolled in the furnished treatment was removed from the study because of a chronic disease that resulted in early mortality. Furnished hutches contained items that we anticipated would allow for grooming, play, or oral behavior. These items included a stationary brush (L-shaped; Rubbermaid 45.7-cm multi-surface push broom); 2 identical artificial teats attached to a PVC T-fitting spaced 0.24 $\mathrm{m}$ apart (1 teat secured perpendicular to the wire paneling, 1 secured at a $45^{\circ}$ angle to the wire paneling; SnapOn Calf Nipple, Tractor Supply Company, Brentwood, $\mathrm{TN})$; a calf "lollie" $(60 \times 7.2 \mathrm{~cm}$ PVC pipe capped on both ends with $9.5-\mathrm{mm}$ holes drilled on 1 side; schedule 40 PVC pipe) filled with a small amount of dry molasses that calves could access if they manipulated the lollie with their mouths; and a rubber chain for calves to manipulate with their mouths or head-butt (JW Pet Invincible Chains Rubber Dog Toy, Amazon, Seattle, WA). Items were spaced approximately $0.6 \mathrm{~m}$ apart and secured to the wire panel pen enclosure with cable ties (Figure 1). The specific placement of items was randomized to 4 equally sized quadrants of the outdoor pen enclosure for each calf and each pen.

\section{Pre-weaning Behavior and Item Use}

Video cameras (1 HD Vixia HG20, 2 HD Vixia HFM30; Canon, Melville, NY) were used to measure calf behavior and item use from 0800 to $2000 \mathrm{~h}$ twice per week when calves were wk $1,3,5$, and 7 of age. Due to technological difficulties, 2 calves were not filmed during wk 3. Cameras were mounted on tripods and positioned in front of pens (approximately $2.4 \mathrm{~m}$ from the pen enclosure at a 30 - to 45-degree angle to maximize the view of the outdoor pen enclosure and items); no more than 4 calves were recorded per camera. The recorded behaviors and their descriptions are listed in Table 1. In addition to the behaviors of interest (locomotor play, sucking on pen fixtures, and item usage), we also recorded time spent in the hutch when the calf was out of view of the camera, and time spent drinking milk replacer (although we could only observe that the calf's head was in the bucket, not that they were actually drinking), to give context to the other behaviors.
Three observers were trained to analyze continuous video recordings using the Noldus Observer software program (Noldus Inc., Wageningen, the Netherlands). Inter-observer reliability was determined using $2 \mathrm{~d}$ of video data for 3 calves; observers were trained until they reached agreement at least $90 \%$ of the time assessed using Cohen's Kappa in the Noldus Observer software program.

\section{Post-weaning Environmental and Social Novelty Tests}

On the day calves were moved into post-weaning groups (63 d of age), they were first moved into a test pen $\left(7.93 \mathrm{~m}^{2}\right)$ for an environmental novelty and social novelty test (adapted from De Paula Vieira et al., 2012). The test arena was triangular, and sides measured $4.28 \mathrm{~m}$ in length. Behaviors were recorded for 15 min per test using a video camera (HD Vixia HG20; Canon) mounted on a tripod in front of the test arena (approximately $3.0 \mathrm{~m}$ from arena at a 30 to $45^{\circ}$ angle). The environmental novelty test preceded the social novelty test for all calves. Because calves were

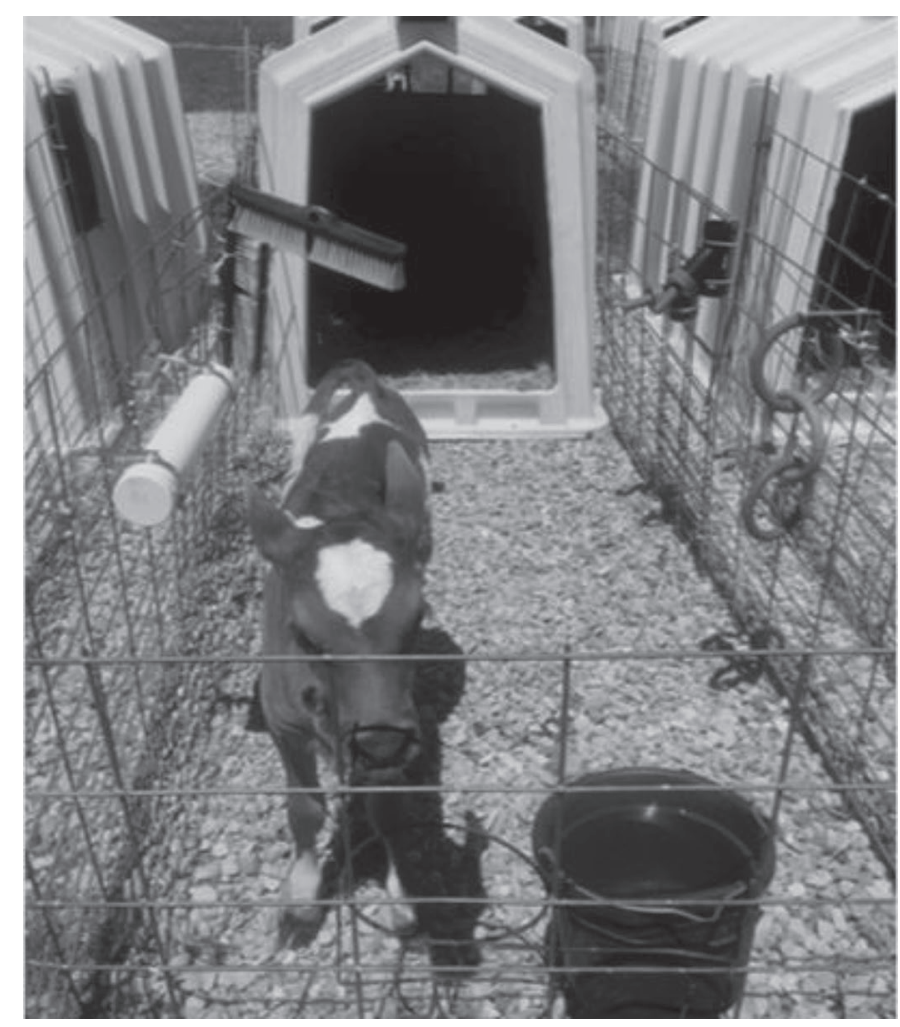

Figure 1. Furnished calf hutch including the calf lollie, stationary brush, artificial teats, and rubber chain. 
Table 1. Ethogram of pre-weaning behaviors recorded continuously from calves during the period from 0800 to $2000 \mathrm{~h}$ for $2 \mathrm{~d}$ during $1,3,5$, and 7 wk of age

\begin{tabular}{ll}
\hline Behavior & Description \\
\hline Sucking pen fixtures & $\begin{array}{l}\text { The calf's mouth is in contact with, or head is oriented toward, the hutch, wire panel enclosure, or metal } \\
\text { bucket holder; does not include items added to the furnished pens } \\
\text { The calf is engaged in a gallop, leap, buck-low, buck-high, buck-kick, or turn (specific definitions of each } \\
\text { behavior were adapted from Jensen et al., 1998); does not include object play with items in the furnished } \\
\text { pens }\end{array}$ \\
Locomotor play & $\begin{array}{l}\text { The calf's mouth is in contact with the teat } \\
\text { or side-to-side motion while in contact with the brush, or can be standing still }\end{array}$ \\
Artificial teat usage & $\begin{array}{l}\text { The calf's mouth or head is in contact with the lollie; calf is standing still or is moving body back and forth } \\
\text { toward the lollie }\end{array}$ \\
Lollie usage & The calf's mouth or head is in contact with the chain; calf is standing still or is moving body back and forth \\
Chain usage & toward the chain \\
Time spent in hutch & The calf's muzzle or head in in the bucket of milk replacer
\end{tabular}

${ }^{1}$ It was unclear from the camera angle if the calf was drinking milk replacer or sucking the sides or bottom of the bucket.

weaned on different days during the experiment, $4.8 \pm$ 2.8 calves were tested per day on 4 different days.

Video recordings from the novelty tests were analyzed continuously by 1 observer using Excel (Microsoft Office, Redmond, WA) and QuickTime Player (Apple Inc., Cupertino, CA). Recordings began after calves were moved into the pen and the experimenter closed the entryway. Intra-observer reliability was evaluated by comparing data records $(\mathrm{n}=3$ calves for the social novelty test and $\mathrm{n}=3$ calves for the environmental novelty test), assessed independently by the same observer, and Pearson correlations averaged (mean $\pm \mathrm{SD}$ ) $0.96 \pm 0.01$.

Environmental Novelty Test. Calves were walked to the test pen via halter by the experimenter, who then exited the testing area and closed the entryway. Unless otherwise stated, behavioral definitions were adapted from De Paula Vieira et al. (2012). Behaviors recorded for the environmental novelty test included walking, pacing (e.g., higher gait speed than normal walking; calf moving back and forth in parallel to the test pen barrier; definition adapted from Johnsen et al., 2015), standing idle, exploratory behavior (e.g., sniffing or licking the ground or pen arena while walking or standing idle with head and neck stretched forward), defecation, vocalization, locomotor play, grazing, and self-grooming.

Social Novelty Test. The social novelty test directly followed the environmental novelty test. The focal calf remained in the test pen after the environmental novelty test, and the experimenter walked a non-focal calf to the test pen using a halter and then exited the testing area. The non-focal calf was either an experimental calf on a different treatment $(\mathrm{n}=8$ calves per treatment) or a non-experimental calf of a similar age $(n=1)$. Calves were used as a non-focal calf for only 1 test each. If an experimental calf was used as a non-focal calf, it always performed the test as the focal calf first. Care was taken to ensure that calves were not paired with calves housed adjacent to them in the hutches, because those calves may not have been unfamiliar. Behaviors included those previously described for the environmental novelty test, in addition to the following: sniffing/licking partner while walking or standing idle, and agonistic social interactions, including head-to-head or head-to-body contact with partner as the initiator (actor) or the receiver (reactor), and kicks directed toward the partner. Although we referred to these behaviors as agonistic, we acknowledge that they may also have been play behaviors.

\section{Starter Intake and Growth}

Starter consumption was measured daily at approximately $1400 \mathrm{~h}$ by the collection of feed refusals. All calves were weighed at birth and weekly thereafter to calculate ADG.

\section{Statistical Analysis}

All data were analyzed using SAS statistical software (version 9.3; SAS Institute Inc., Cary, NC) using calf as the experimental unit of analysis. The normality and homogeneity of variances of the raw data for all variables were tested using the UNIVARIATE procedure of SAS, and the frequency distribution of the residuals were visually inspected. Calf pair was originally included in the model but was not significant, so it was removed. All pre-weaning behaviors were not normally distributed, so they were square-root-transformed before analysis. For all mixed models, the between-within method of degrees of freedom was used. Significant differences were declared at $P \leq 0.05$ and a trend at 0.05 $>P \leq 0.10$. 
To determine the duration and frequency of item use, as well as the effect of treatment on play behavior and sucking pen fixtures pre-weaning, the behavior durations and frequencies were summed for each calf and $12 \mathrm{~h}$ observation period. Behavior did not differ by observation day within week, so these data were averaged across the $2 \mathrm{~d}$ per week. An initial analysis revealed no difference between use of the straight or angled teat, so these variables were combined as 1 item. To ensure that any changes in behavior across week of age was unaffected by gradual changes in THI across time, preliminary screening for a THI $\times$ week interaction was conducted; results revealed no collinearity between week and THI.

To compare the use of items in the furnished hutch across weeks, a repeated measures ANOVA (PROC MIXED) was used; the model included item as a fixed effect (teats, brush, lollie, and chain), week of age as a repeated measure, THI as a continuous covariate, and an item $\times$ week interaction. Calf was considered the subject in the repeated statement, and a compound symmetry covariance structure was chosen based on best fit. Based on visual inspection of the graphs, specific post hoc pairwise comparisons were made between the brush and other items using contrast statements in SAS.

To determine the use of items across hours of the day, we categorized the hourly data into 4 periods of 3 $\mathrm{h}$ : morning (0800 to $1059 \mathrm{~h}$ ), midday (1100 to $1359 \mathrm{~h}$ ), afternoon (1400 to $1659 \mathrm{~h}$ ), and post-feeding (1700 to $1959 \mathrm{~h}$ ). The use of items across the day was tested using a repeated measures ANOVA (PROC MIXED) that included item as a fixed effect, period as a repeated measure, and an item $\times$ period interaction. Calf was included as the subject, and an autoregressive covariance structure was chosen based on best fit. Based on visual inspection of the diurnal pattern, we were most interested in comparing the post-feeding period (1700 to $1959 \mathrm{~h}$ ) to the 3 other periods; these pairwise comparisons were done using contrast statements in SAS.

To compare play behavior, sucking pen fixtures, time spent drinking milk, and time spent in the hutch between calves housed in furnished versus standard hutches, a repeated-measures ANOVA (PROC MIXED) was used; the model included treatment (standard vs. furnished hutch) as a fixed effect, week of age as a repeated measure, THI as a continuous covariate, and a treatment $\times$ week interaction. Calf was considered the subject in the repeated statement, and a compound symmetry covariance structure was chosen based on best fit.

To determine if the effect of treatment on locomotor play or sucking on pen fixtures differed by time of day, we categorized hourly data into four 3-h: morning (0800 to $1059 \mathrm{~h}$ ), midday (1100 to $1359 \mathrm{~h}$ ), afternoon
(1400 to $1659 \mathrm{~h}$ ), and post-feeding (1700 to $1959 \mathrm{~h}$ ). The effect of treatment on diurnal play and sucking behavior was tested using a repeated measures ANOVA (PROC MIXED) that included treatment (standard vs. furnished hutch) as a fixed effect, period as a repeated measure, and a treatment $\times$ period interaction. Calf was included as the subject, and an autoregressive covariance structure was chosen based on best fit. Moderate treatment $\times$ period interactions were detected for time spent in locomotor play $(P=0.07)$ and frequency of play bouts $(P=0.10)$, so data were analyzed separately by period post hoc.

To determine the effect of pre-weaning housing on response to novelty post-weaning, we summed behavior durations and frequencies collected during the environmental and social novelty tests per calf and behavior. An ANOVA (PROC GLM) was used to compare the behavior of calves on each treatment; the model included treatment (standard vs. furnished hutch) as a fixed effect.

To determine the effect of pre-weaning housing on BW, ADG, and starter intake, data were averaged per week and calf. In a preliminary analysis, we included THI in these models in case the weather had an effect on growth or starter intake, but we observed no effect of THI on these outcomes, so it was left out of the final models. A repeated measures ANOVA (PROC MIXED) was used to compare calves housed in each hutch type; the model included treatment (standard vs. furnished hutch) as a fixed effect, week as a repeated measure, birth measures (birth weight and height) as continuous covariates, and a treatment $\times$ week interaction. Calf was considered the subject in the repeated statement, and the first-order autoregressive covariance structure was chosen based on best fit. Differences in ADG were assessed using ANOVA (PROC GLM); the model included treatment (standard vs. furnished hutch) as a fixed effect.

\section{RESULTS}

\section{Pre-weaning Behavior and Item Use}

Calves used all items in the furnished hutch throughout the experiment, and item usage increased as calves got older (Figure $2 ; F_{3,24}=9.02, P_{\mathrm{wk}}=0.0004$ ). Calves spent a different amount of time with each item throughout the experiment $\left(F_{3,23}=28.62, P_{\text {item }}\right.$ $<0.0001)$ and used the items differently depending on week of age $\left(F_{9,61}=2.63, P_{\text {item } \times \text { wk }}=0.01\right)$. Specific pairwise comparisons revealed that calves spent the most time with the brush compared with the other items $(P<0.05$ for all comparisons between the brush and other items), and brush use increased the most across 

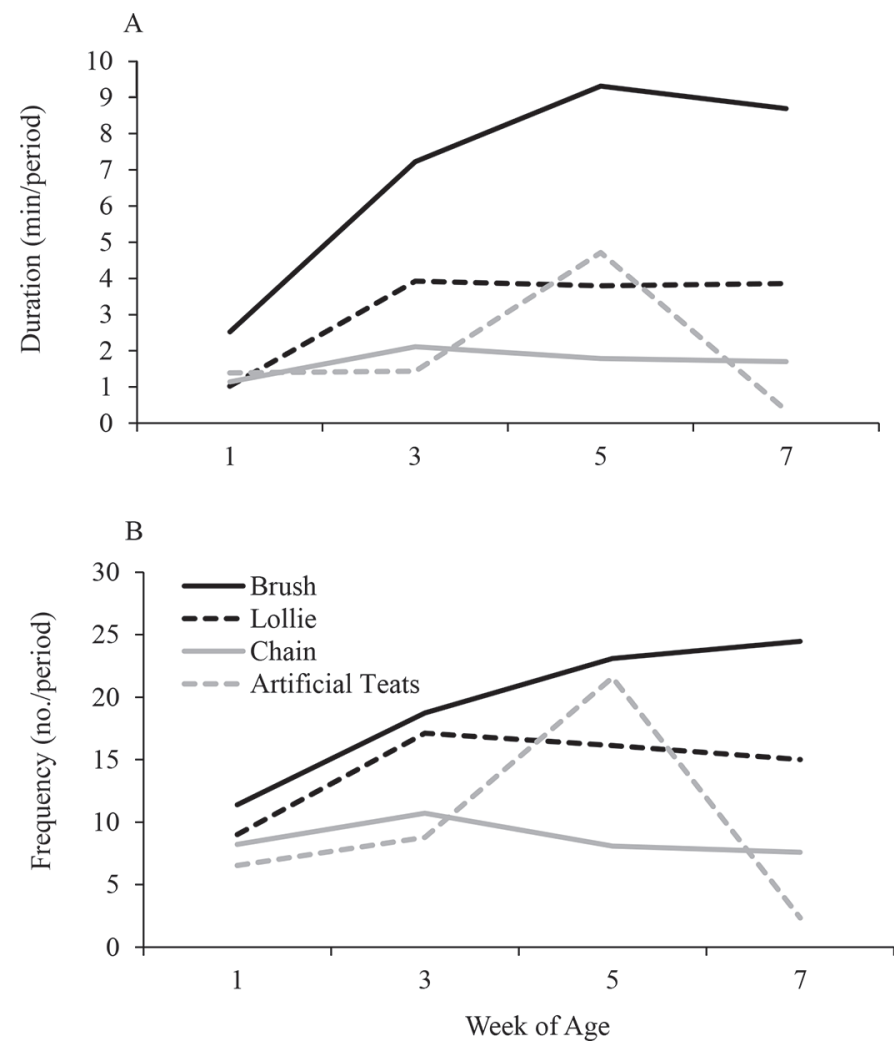

Figure 2. (A) Mean duration, and (B) frequency of item use for calves housed in furnished hutches $(\mathrm{n}=9$ calves) during wk $1,3,5$, and 7 of age. Square root transformation was applied to all variables; back-transformed LSM are presented.

weeks compared with the other items. Similarly, the frequency of item usage was also affected by the type of item $\left(F_{3,23}=10.23, P_{\text {item }}<0.0001\right)$ and increased with week of age $\left(F_{3,24}=5.28, P_{\mathrm{wk}}=0.006\right)$. Pairwise comparisons revealed that calves used the brush more frequently than the other items $(P<0.05$ for all comparisons between the brush and other items). However, we observed no week $\times$ item interaction for frequency of item use $\left(F_{9,61}=1.69, P_{\text {item } \times \text { wk }}=0.11\right)$.

When the data were summed by 3 -h period, the duration spent with each item was different (Figure $\left.3 ; F_{3,23}=54.21, P_{\text {item }}<0.0001\right)$ and was affected by period $\left(F_{3,24}=63.69, P_{\text {period }}<0.0001\right)$. Calves used all of the items the most during the 3 -h period after feeding $(1700$ to $1959 \mathrm{~h})$ compared with other periods $(P$ $<0.0001$ for all comparisons between the post-feeding period and other periods for all items).

Calves housed in furnished hutches spent more time engaged in locomotor play (Figure $4 ; F_{1,17}=5.86, P_{\text {trt }}$ $=0.03)$ and had more bouts of play $\left(F_{1,17}=4.67, P_{\mathrm{trt}}=\right.$ $0.04)$ than calves housed in standard environments. Regardless of treatment, play behavior tended to decrease across week of age (duration: $F_{348}=2.45, P_{\text {wk }}=0.07$; frequency: $\left.F_{3,48}=2.55, P_{\mathrm{wk}}=0.06\right)$.

When the data were summed by 3 -h period, play behavior increased over the course of the day (duration: $F_{3,51}=23.9, P_{\text {period }}<0.0001$; frequency: $F_{3,51}=$ 29.5, $\left.P_{\text {period }}<0.0001\right)$. We observed a tendency for treatments to affect play behavior differently based on period (duration: $F_{3,51}=2.42, P_{\text {trt } \times \text { wk }}=0.07$; frequency: $\left.F_{3,51}=2.19, P_{\text {trt } \times \mathrm{wk}}=0.10\right)$. Post hoc analyses revealed that calves in the furnished hutches spent more time playing $(P=0.004)$ and had higher play bouts $(P=$ 0.01 ) during the $3 \mathrm{~h}$ after feeding (1700 to $1959 \mathrm{~h}$ ), but we observed no differences between treatments at other periods.

We observed no effect of the furnished hutches on the amount of time calves spent sucking pen fixtures (Figure $4 ; F_{1,17}=1.24, P_{\text {trt }}=0.28$ ) or the number of sucking bouts $\left(F_{1,17}=0.04, P_{\text {trt }}=0.83\right)$ when data were summed by week. We observed an effect of week on sucking duration and frequency, in that sucking increased as calves aged (duration: $F_{3,48}=9.74, P_{\mathrm{wk}}<$ 0.001; frequency: $\left.F_{3,48}=10.47, P_{\mathrm{wk}}<0.0001\right)$.

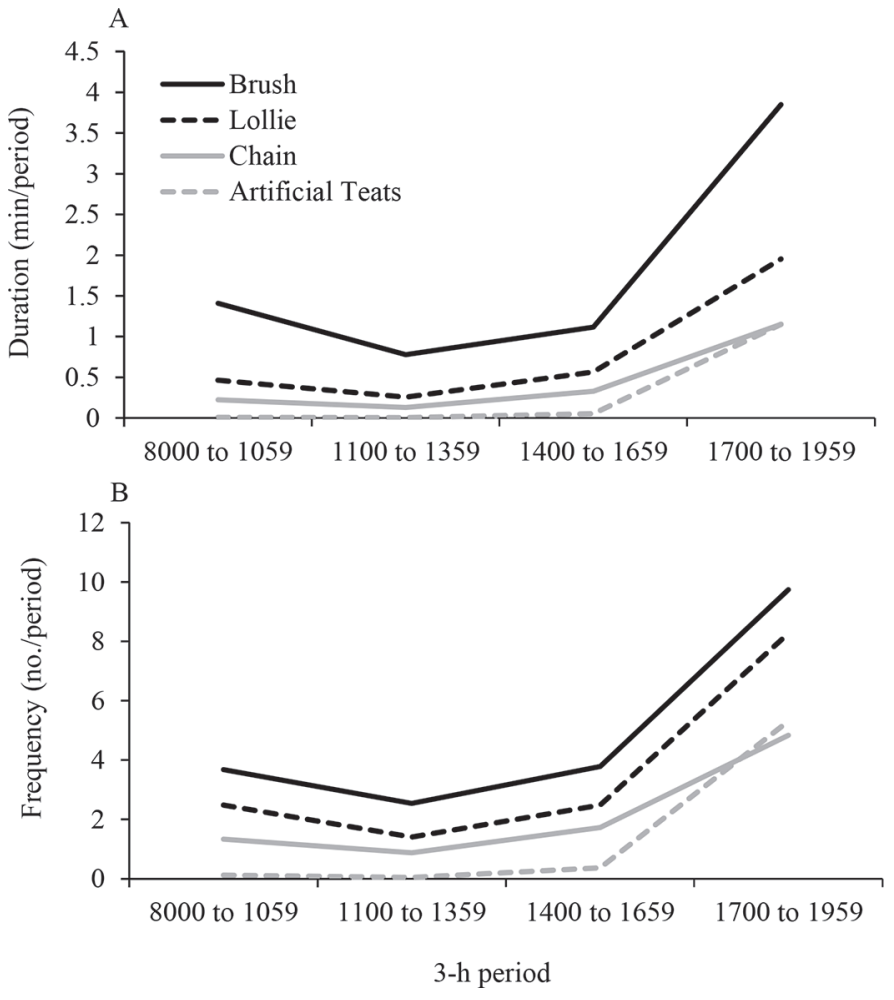

Figure 3. (A) Mean duration, and (B) frequency of item use by 3-h period for calves housed in furnished hutches $(n=9)$ averaged across wk 1, 3, 5, and 7 of age. Square root transformation was applied to all variables; back-transformed LSM are presented. 
When data were averaged across $3 \mathrm{~h}$ period, time spent sucking on pen fixtures and the number of sucking bouts increased across period (Figure 5; duration: $F_{3,51}=88.40, P_{\text {period }}<0.0001 ;$ frequency: $F_{3,51}=138.05$, $\left.P_{\text {period }}=<0.0001\right)$, but we observed no interaction between treatment and period (duration: $F_{3,51}=1.12$, $P_{\text {trt } \times \text { period }}=0.35$; frequency: $F_{3,51}=0.14, P_{\text {trt } \times \text { period }}=$ $0.94)$.

Regardless of treatment, calves spent about 3.5 $\mathrm{min} / 12 \mathrm{~h}$ drinking milk replacer in the first $5 \mathrm{wk}$ of life (during wk 7 no milk replacer was available; $F_{1,17}$ $\left.=0.03, P_{\text {trt }}=0.86\right)$ and spent $584 \mathrm{~min} / 12 \mathrm{~h}(9.7 \mathrm{~h} / 12$ h) in the hutch and out of view of the camera $\left(F_{1,17}=\right.$ $\left.0.01, P_{\text {trt }}=0.97\right)$. Time spent drinking milk was unaffected by week of age $\left(F_{2,31}=0.06, P_{\mathrm{wk}}=0.94\right)$, but time spent in the hutch decreased as calves got older $\left(F_{3,51}=8.31, P_{\mathrm{wk}}=0.0001\right)$.
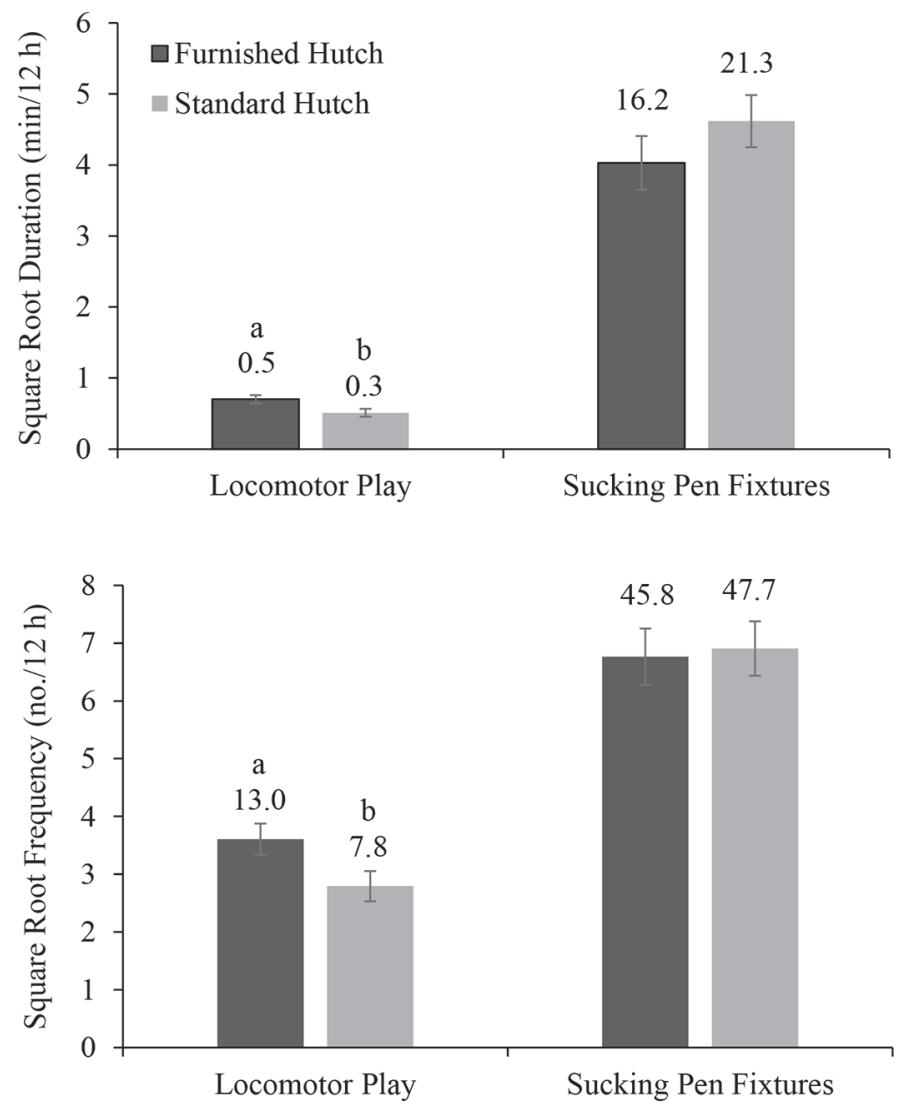

Figure 4. (top) Square root mean ( \pm SEM) duration, and (bottom) frequency of locomotor play behavior and sucking pen fixtures for calves housed in standard ( $\mathrm{n}=10$ calves) or furnished ( $\mathrm{n}=9$ calves) hutches at wk 1, 3, 5, and 7 of age. Square root transformation was applied to both variables; back-transformed LSM are presented above each column. Different letters $(\mathrm{a}, \mathrm{b})$ represent significant differences between treatments at $P \leq 0.05$.

\section{Post-weaning Environmental and Social Novelty Tests}

Results from the environmental and social novelty tests are shown in Table 2; we observed no effect of treatment on calves' behavioral response to environmental or social novelty.

\section{Starter Intake and Growth}

Body weight was similar for calves housed in furnished and standard hutches (Table $3 ; F_{1,16}=1.05, P=$ 0.32), and we observed no difference in ADG between treatments. Treatment did not affect starter intake $\left(F_{1,17}=1.00, P=0.41\right)$.

\section{DISCUSSION}

Our objectives were to determine whether calves used items added to their standard hutch, and whether these items affected calf play and sucking behavior, re-
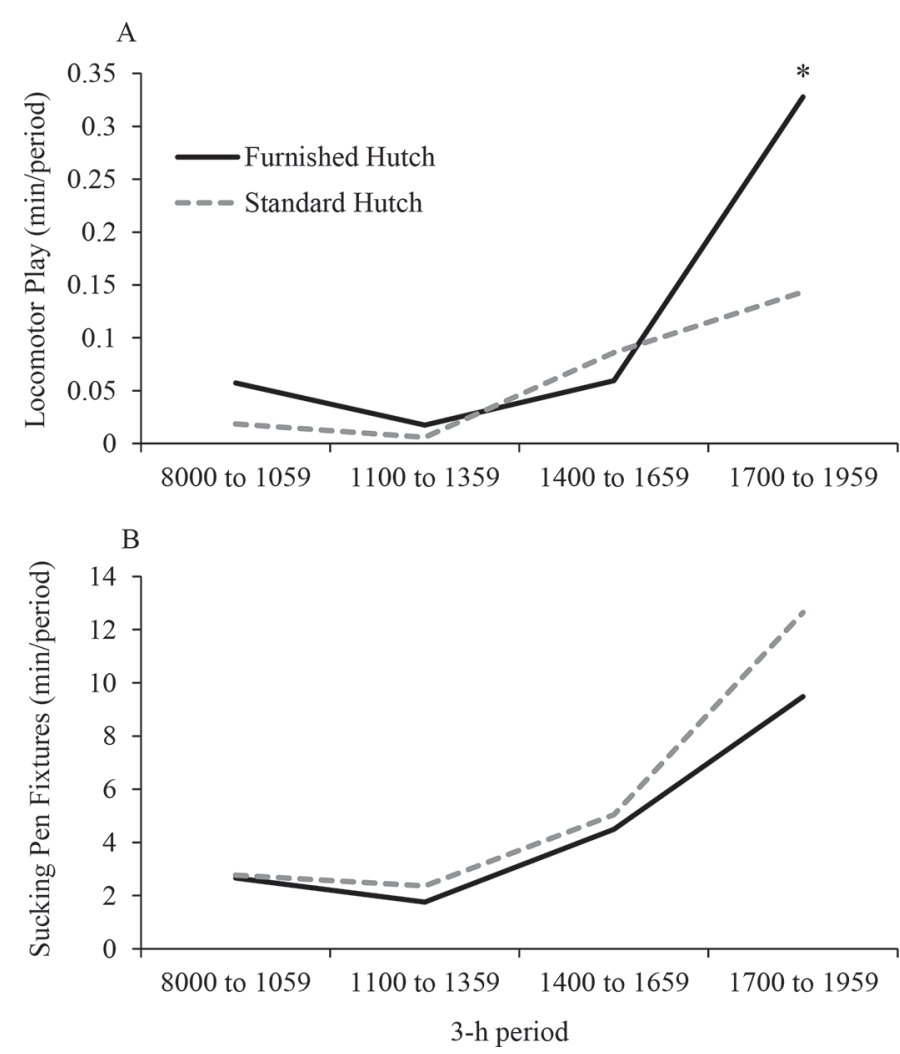

Figure 5. (A) Mean of locomotor play behavior, and (B) sucking pen fixtures by 3 -h period for calves housed in standard $(\mathrm{n}=10)$ or furnished $(\mathrm{n}=9)$ hutches averaged across wk 1, 3, 5, and 7 of age. Square root transformation was applied to both variables; back-transformed LSM are presented. An asterisk $\left(^{*}\right)$ represents a significant difference at $P \leq 0.05$ between treatments. 
Table 2. Behavioral responses (mean \pm SEM) of calves housed in standard $(\mathrm{n}=10$ calves) or furnished ( $\mathrm{n}$ $=9$ calves) hutches during the environmental and social novelty tests conducted when calves were $63 \mathrm{~d}$ old $^{1}$

\begin{tabular}{|c|c|c|c|c|}
\hline Test & Standard hutch & Furnished hutch & SEM & $P$-value \\
\hline \multicolumn{5}{|l|}{ Environmental novelty test } \\
\hline Standing idle (s/test) & 434 & 400 & 116 & 0.53 \\
\hline Pacing (s/test) & 25.0 & 20.3 & 18.3 & 0.59 \\
\hline Walking (s/test) & 58.1 & 6.1 & 33.3 & 0.61 \\
\hline Grazing (s/test) & 107 & 104 & 99.0 & 0.94 \\
\hline Locomotor play (s/test) & $4.2(17.5)$ & $5.3(27.8)$ & 22.7 & 0.31 \\
\hline Self-grooming (s/test) & $3.6(6.5)$ & $1.6(2.7)$ & 1.6 & 0.23 \\
\hline Sucking pen fixtures (s/test) & $3.6(13.1)$ & $5.2(26.8)$ & 4.1 & 0.43 \\
\hline Exploring (s/test) & 210 & 214 & 58.4 & 0.90 \\
\hline Defecation (no./test) & 1.7 & 2.3 & 1.1 & 0.24 \\
\hline Vocalization (no./test) & $4.1(16.8)$ & $4.2(18.1)$ & 2.1 & 0.87 \\
\hline \multicolumn{5}{|l|}{ Social novelty test } \\
\hline Standing idle (s/test) & 323 & 371 & 94.6 & 0.27 \\
\hline Walking (s/test) & 90.9 & 101 & 49.0 & 0.66 \\
\hline Grazing $(\mathrm{s} / \text { test })^{2}$ & $4.7(22.4)$ & $4.8(23.5)$ & 4.7 & 0.96 \\
\hline Locomotor play (s/test) & $4.1(16.4)$ & $3.2(10.0)$ & 2.5 & 0.46 \\
\hline Self-grooming (s/test) & $2.3(5.3)$ & $2.1(4.5)$ & 1.8 & 0.85 \\
\hline Sucking pen fixtures (s/test) & $0.8(0.7)$ & $1.0(1.0)$ & 1.5 & 0.80 \\
\hline Social grooming (s/test) & $13.0(168)$ & $13.0(168)$ & 4.1 & 0.99 \\
\hline Exploring (s/test) & 133 & 134 & 65.5 & 0.98 \\
\hline Defecation (no./test) & $0.5(0.3)$ & $0.5(0.3)$ & 0.6 & 0.99 \\
\hline Vocalizations (no./test) & $1.6(2.6)$ & $2.5(6.1)$ & 2.1 & 0.37 \\
\hline Agonistic ${ }^{2}$ : actor (no./test) & $2.6(6.8)$ & $1.3(1.7)$ & 1.6 & 0.10 \\
\hline Agonistic $^{2}$ : reactor (no./test) & $2.2(4.9)$ & $2.2(4.7)$ & 1.4 & 0.93 \\
\hline Kicks (no./test) & $1.2(1.4)$ & $0.8(0.7)$ & 0.8 & 0.32 \\
\hline
\end{tabular}

${ }^{1}$ For variables where square root transformation was applied, back-transformed LSM are provided in parentheses.

${ }^{2}$ It is not clear if calves were acting agonistically or merely playing with their partners.

sponse to environmental and social novelty post-weaning, starter intake, and growth. We determined that calves used all of the items we added to the furnished hutch; item use depended on the time of day, and use increased as calves got older. Calves housed in the furnished hutches spent almost $50 \%$ more time engaged in locomotor play than those housed in standard hutches, but we observed no effect of the furnished hutch on time spent sucking pen fixtures, growth, starter intake, or response to novelty.

Overall, calves spent $80 \%$ their time in the hutch $(9.7 \mathrm{~h} / 12 \mathrm{~h})$, leaving only $20 \%$ of their time spent in the outdoor area with the items (about $2.3 \mathrm{~h} / 12 \mathrm{~h}$ ). Despite the short amount of time they spent outside, calves housed in the furnished hutches used all of the provided items throughout the experiment, and item use increased with age. The increase in item use may have been partially driven by an increase in time spent outside the hutch where the items were located, or may have reflected an increased motivation for oral or grooming behaviors as the calves aged.

Calves housed in the furnished hutches used the stationary brush for longer periods than the other items, and this difference was consistent across week of age. Calves increased their use of the brush from about 2.5 $\min / 12 \mathrm{~h}$ to just over $9 \mathrm{~min} / 12 \mathrm{~h}$ by the end of the experiment. Although this was only a short period of time, it was comparable to reported use of automated brushes by adult dairy cows ( 5 to $7 \mathrm{~min} / \mathrm{d}$; DeVries et al., 2007; Val-Laillet et al., 2008). Bolinger et al. (1997) determined that cows will increase time spent grooming after a period of restraint, suggesting that the behavior is important to them. The purpose of grooming as an adult is thought to be for general cleanliness and parasite removal (Simonsen, 1979), but less is known about the role of grooming to the young calf. Calves

Table 3. Mean $( \pm$ SEM) BW, ADG, and starter intake for calves housed in standard ( $\mathrm{n}=10$ calves $)$ or furnished ( $\mathrm{n}=9$ calves) hutches from birth until after $63 \mathrm{~d}$ of age

\begin{tabular}{lcccc}
\hline Variable & Standard hutch & Furnished hutch & SEM & $P$-value \\
\hline BW $(\mathrm{kg})$ & 40.7 & 42.0 & 0.9 & 0.32 \\
$\mathrm{ADG}(\mathrm{kg} / \mathrm{d})$ & 0.61 & 0.67 & 0.1 & 0.21 \\
Starter intake $(\mathrm{kg} / \mathrm{d})$ & 0.60 & 0.67 & 0.1 & 0.41 \\
\hline
\end{tabular}


are intensively groomed by their dams in the few hours after birth (Jensen, 2012), and grooming by the dam is considered important for the development of the bond between the dam and calf (von Keyserlingk and Weary, 2007). More research is encouraged to determine the importance of grooming for young calves.

The calf lollie, artificial teats, and rubber chain were used less often than the stationary brush, and use plateaued after 3 wk of age. However, this finding does not necessarily indicate calf preference for 1 item over the others, because these items encouraged different behaviors (grooming vs. sucking or oral manipulation), and use depended on time of day. All items were used most during the $3 \mathrm{~h}$ after milk replacer delivery, when calves were expected to be most active (Jensen et al., 1998) and were spending more time outside the hutch, where the items were located. Calves are especially motivated to suckle after feeding, because this behavior is known to be stimulated by the ingestion of milk (de Passillé, 2001) and may be especially high when calves are fed with buckets instead of teats (Appleby et al., 2001). The increased use of the brush may also have been driven by other behaviors associated with nursing, such as head-butting the udder, but more research is needed. We also cannot rule out the idea that the provision of 4 different items could have influenced the time spent with each item; for example, the use of the artificial teat may have been higher if the other items had not been available.

We observed no effect of the furnished hutch on the amount of time calves spent sucking on pen fixtures, despite an increase in the use of items that were meant to provide other outlets for sucking behavior after milk replacer feeding. Calves spent only about 3.5 min drinking milk replacer during the afternoon meal, much less than calves provided ad libitum milk through a teat (47 min/d for 2 meals; Appleby et al., 2001). In previous studies, the provision of an artificial teat has been documented to reduce sucking on peers and objects in the pen (Jung and Lidfors, 2001; Loberg and Lidfors, 2001); however, in these previous studies calves were given the opportunity to drink their milk through the teat, and then had access to a dry teat post-feeding. In a study of male veal calves that were fed milk replacer from a bucket and provided with a dry teat near the bucket post-feeding, Veissier et al. (2002) found that calves spent 2.6 min using the dry teat, and half as much time "nibbling" on parts of the pen as calves without a dry teat. The difference in results between our study and Veissier et al. (2002) could have been driven by sex, housing, characteristics of the milk replacer, or the placement of artificial teats (or other items) relative to the milk bucket. In our case, the items were placed at the sides of the pens, and calves were often seen sucking on the metal bucket holder or the wire panel at the front of the pen. Further research is required to determine the optimal location of an artificial teat or other items meant to discourage non-nutritive sucking or nibbling on pen surfaces.

The addition of items to a standard hutch increased locomotor play behavior in calves, especially in the 3 $\mathrm{h}$ after milk replacer feeding. This peak post-feeding may have corresponded to natural increases in the motivation to play, or may have been stimulated by external factors associated with feeding time (Jensen et al., 1998). Calves housed in the furnished hutches spent about $30 \mathrm{~s}$ engaged in locomotor play throughout the $12 \mathrm{~h}$ observation period, less than has been previously reported. For example, Jensen et al. (2015) reported that individually housed calves performed $2 \mathrm{~min} / \mathrm{d}$ of locomotor play when they were housed in larger pens $(3.0 \mathrm{~m} \times 4.5 \mathrm{~m}$ vs. $1.2 \times 2.7 \mathrm{~m})$, and they were offered more milk $(5$ or $9 \mathrm{~L} / \mathrm{d})$ than calves in our study $(4.5$ L/d of milk replacer). Although locomotor play was higher in calves housed in furnished hutches, the standard milk allowance and pen size provided in this study likely reduced overall play behavior. The timing of our observation period may have also missed some important periods where play could be expected, such as at the morning feeding (Jensen et al., 1998). Locomotor play is considered an indicator of good welfare (Jensen et al., 1998; Jensen and Kyhn, 2000); play decreases when environmental conditions are challenging (Held and Špinka, 2011), suggesting its use as an indicator that an animal is coping well with its environment. We encourage further work assessing the effect of the physical complexity of housing on play behavior, in addition to social housing, higher space allowance, and higher milk allowance.

Housing calves in the furnished hutch did not affect their behavioral response to environmental or social novelty post-weaning in our study. In contrast, other studies have shown that barren housing can increase an animal's behavioral response to novel situations (dairy calves: Jensen et al., 1997; De Paula Vieira et al., 2012; domestic chicks: Jones and Waddington, 1992). However, these studies either introduced novel items to the pen enclosure periodically (Jones and Waddington, 1992) or provided social enrichment (Jensen et al., 1997; De Paula Vieira et al., 2012). In our study, items remained in the pen enclosure throughout the experimental period, and new items were not introduced. Thus, we may have created a static environment that was not complex enough to elicit behavioral change in novel situations. Future research should aim to create a more complex environment for dairy calves though physical and social enrichment and investigate the effect on calf reactivity to novelty. 
We found no effect of the furnished hutch on starter intake or calf growth. Although our predictions about this measure were not as strong as those for our behavioral measures, we expected to see a moderate stimulation in starter intake driven by more activity and play. In a study assessing the effect of social housing on starter intake, De Paula Vieira et al. (2010) found that pair-housed calves consumed 30\% more starter than individually housed calves. This increase in intake may have been driven by a combination of increased play activity and social learning (calves learning from each other). In other species, the provision of physical enrichments increased feed intake and growth (Van de Weerd et al., 1997; Beattie et al., 2000); however, most of the enrichments used, such as straw or nesting material, also likely affected thermoregulation and energy conservation. For example, Van de Weerd et al. (1997) reported higher BW for mice housed in cages with nesting material compared with those housed in standard cages, despite the fact that mice in the standard cages consumed more food. In addition, Beattie et al. (2000) reported higher feed intake, growth rates and heavier carcass weights at finishing for pigs given extra space and a space with peat and straw.

A lack of growth response may have also been driven by the low milk allowance $(4.5 \mathrm{~L} / \mathrm{d})$ provided, regardless of treatment. Providing unlimited milk pre-weaning has been shown to increase growth performance in Jersey (Uys et al., 2011) and Holstein calves (Appleby et al., 2001). More research is needed to determine whether other forms of physical enrichment, such as those that encourage feed intake or energy conservation, can affect calf growth.

\section{CONCLUSIONS}

Calves used all of the items provided in the furnished hutch, and use depended on week of life and time of day. The furnished hutch increased the amount of time calves engaged in locomotor play but did not change the amount of time calves spent sucking on pen fixtures, their response to novelty, starter intake, or growth. We encourage further research to determine other forms of physical enrichment, as well as any benefits in combining social and physically complexity in the housing environments of young dairy calves.

\section{ACKNOWLEDGMENTS}

The authors are thankful for the cooperation of the students and staff of Waterman Dairy Center, and for their assistance throughout this research trial. We also express gratitude to Hannah Manning, Emily Cosen- tino, and Priscila Bernhard from The Ohio State University for their assistance with data collection.

\section{REFERENCES}

Appleby, M., D. M. Weary, and B. Chua. 2001. Performance and feeding behaviour of calves on ad libitum milk from artificial teats. Appl. Anim. Behav. Sci. 74:191-201.

Beattie, V. E., N. E. O'Connell, and B. W. Moss. 2000. Influence of environmental enrichment on the behaviour, performance and meat quality of domestic pigs. Livest. Prod. Sci. 65:71-79.

Boissy, A., G. Manteuffel, M. B. Jensen, R. O. Moe, B. Spruijt, L. J. Keeling, C. Winckler, B. Forkman, I. Dimitrov, J. Langbein, and M. Bakken. 2007. Assessment of positive emotions in animals to improve their welfare. Physiol. Behav. 92:375-397.

Bolinger, D. J., J. L. Albright, J. Morrow-Tesch, S. J. Kenyon, and M. D. Cunningham. 1997. The effects of restraint using self-locking stanchions on dairy cows in relation to behavior, feed intake, physiological parameters, health, and milk yield. J. Dairy Sci. 80:2411-2417.

Dawes, M. E., J. W. Tyler, D. Hostetler, J. Lakritz, and R. Tessman. 2002. Evaluation of a commercially available immunoassay for assessing adequacy of passive transfer in calves. J. Am. Vet. Med. Assoc. 220:791-793.

de Passillé, A. M. 2001. Sucking motivation and related problems in calves. Appl. Anim. Behav. Sci. 72:175-187.

De Paula Vieira, A., A. M. de Passillé, and D. M. Weary. 2012. Effects of the early social environment on behavioral responses of dairy calves to novel events. J. Dairy Sci. 95:5149-5155.

De Paula Vieira, A., M. A. G. Von Keyserlingk, and D. M. Weary. 2010. Effects of pair versus single housing on performance and behavior of dairy calves before and after weaning from milk. J. Dairy Sci. 93:3079-3085.

DeVries, T. J., M. Vankova, D. M. Veira, and M. A. G. Von Keyserlingk. 2007. Short communication: Usage of mechanical brushes by lactating dairy cows. J. Dairy Sci. 90:2241-2245.

Gaillard, C., R. K. Meagher, M. A. G. von Keyserlingk, and D. M. Weary. 2014. Social housing improves dairy calves' performance in two cognitive tests. PLoS One 9:e90205.

Held, S. D., and M. Špinka. 2011. Animal play and animal welfare. Anim. Behav. 81:891-899.

Jensen, M. B. 2012. Behaviour around the time of calving in dairy cows. Appl. Anim. Behav. Sci. 139:195-202.

Jensen, M. B., and M. Budde. 2006. The effects of milk feeding method and group size on feeding behavior and cross-sucking in grouphoused dairy calves. J. Dairy Sci. 89:4778-4783.

Jensen, M. B., L. R. Duve, and D. M. Weary. 2015. Pair housing and enhanced milk allowance increase play behavior and improve performance in dairy calves. J. Dairy Sci. 98:2568-2575.

Jensen, M. B., and R. Kyhn. 2000. Play behaviour in group-housed dairy calves, the effect of space allowance. Appl. Anim. Behav. Sci. $67: 35-46$.

Jensen, M. B., K. S. Vestergaard, and C. C. Krohn. 1998. Play behaviour in dairy calves kept in pens: The effect of social contact and space allowance. Appl. Anim. Behav. Sci. 56:97-108.

Jensen, M. B., K. S. Vestergaard, C. C. Krohn, and L. Munksgaard. 1997. Effect of single versus group housing and space allowance on responses of calves during open-field tests. Appl. Anim. Behav. Sci. 54:109-121.

Johnsen, J. F., K. Ellingsen, A. M. Grøndahl, K. E. Bøe, L. Lidfors, and C. M. Mejdell. 2015. The effect of physical contact between dairy cows and calves during separation on their post-separation behavioural response. Appl. Anim. Behav. Sci. 166:11-19.

Jones, R. B., and D. Waddington. 1992. Modification of fear in domestic chicks, Gallus gallus domesticus, via regular handling and early environmental enrichment. Anim. Behav. 43:1021-1033.

Jung, J., and L. Lidfors. 2001. Effects of amount of milk, milk flow and access to a rubber teat on cross-sucking and non-nutritive sucking in dairy calves. Appl. Anim. Behav. Sci. 72:201-213. 
Loberg, J., and L. Lidfors. 2001. Effect of milk flow rate and presence of a floating nipple on abnormal sucking between dairy calves. Appl. Anim. Behav. Sci. 72:189-199.

Mandel, R., H. R. Whay, E. Klement, and C. J. Nicol. 2016. Invited review: Environmental enrichment of dairy cows and calves in indoor housing. J. Dairy Sci. 99:1695-1715.

Mintline, E. M., M. Stewart, A. R. Rogers, N. R. Cox, G. A. Verkerk, J. M. Stookey, J. R. Webster, and C. B. Tucker. 2013. Play behavior as an indicator of animal welfare: Disbudding in dairy calves. Appl. Anim. Behav. Sci. 144:22-30.

Newberry, R. C. 1995. Environmental enrichment: Increasing the biological relevance of captive environments. Appl. Anim. Behav. Sci. 44:229-243.

Pempek, J. A., M. L. Eastridge, S. S. Swartzwelder, K. M. Daniels, and T. T. Yohe. 2016. Housing system may affect behavior and growth performance of Jersey heifer calves. J. Dairy Sci. 99:569-578.

Rushen, J., and A. M. de Passillé. 1995. The motivation of non-nutritive sucking in calves, Bos taurus. Anim. Behav. 49:1503-1510.

Simonsen, H. B. 1979. Grooming behavior of domestic cattle. Nord. Vet. Med. 31:1-5.

Stull, C., and J. Reynolds. 2008. Calf welfare. Vet. Clin. North Am. Food Anim. Pract. 24:191-203.

USDA. 2016. Dairy 2014: Dairy Cattle Management Practices in the United States, 2014. USDA-APHIS-VS-CEAH-NAHMS, Fort Collins, CO. \#692.0216.
Uys, J. L., D. C. Lourens, and P. N. Thompson. 2011. The effect of unrestricted milk feeding on the growth and health of Jersey calves. J. S. Afr. Vet. Assoc. 82:47-52.

Val-Laillet, D., D. M. Veira, and M. A. G. Von Keyserlingk. 2008. Short communication: Dominance in free-stall-housed dairy cattle is dependent upon resource. J. Dairy Sci. 91:3922-3926.

Van de Weerd, H. A., P. L. P. Van Loo, L. F. M. Van Zutphen, J. M. Koolhaas, and V. Baumans. 1997. Nesting material as environmental enrichment has no adverse effects on behavior and physiology of laboratory mice. Physiol. Behav. 62:1019-1028.

Veissier, I., A. M. de Passillé, G. Després, J. Rushen, I. Charpentier, A. R. Ramirez De La Fe, and P. Pradel. 2002. Does nutritive and non-nutritive sucking reduce other oral behaviors and stimulate rest in calves? J. Anim. Sci. 80:2574-2587.

von Keyserlingk, M. A., and D. M. Weary. 2007. Maternal behavior in cattle. Horm. Behav. 52:106-113.

Zimbelman, R. B., and R. J. Collier. 2011. Feeding strategies for highproducing dairy cows during periods of elevated heat and humidity. Pages 111-126 in Proc. 2011 Tri-State Dairy Nutrition Conf., Fort Wayne, IN. The Ohio State University, Columbus.

Zimmermann, A., M. Stauffacher, W. Langhans, and H. Würbel. 2001. Enrichment-dependent differences in novelty exploration in rats can be explained by habituation. Behav. Brain Res. 121:11-20. 